\title{
Development and validation of a detailed TRNSYS-Matlab model for large solar collector fields for district heating applications
}

\author{
Bava, Federico; Furbo, Simon
}

\section{Published in:}

Energy

Link to article, DOI:

10.1016/j.energy.2017.06.146

Publication date:

2017

Document Version

Peer reviewed version

Link back to DTU Orbit

Citation (APA):

Bava, F., \& Furbo, S. (2017). Development and validation of a detailed TRNSYS-Matlab model for large solar collector fields for district heating applications. Energy, 135, 698-708.

https://doi.org/10.1016/j.energy.2017.06.146

\section{General rights}

Copyright and moral rights for the publications made accessible in the public portal are retained by the authors and/or other copyright owners and it is a condition of accessing publications that users recognise and abide by the legal requirements associated with these rights.

- Users may download and print one copy of any publication from the public portal for the purpose of private study or research.

- You may not further distribute the material or use it for any profit-making activity or commercial gain

- You may freely distribute the URL identifying the publication in the public portal 


\section{Development and validation of a detailed TRNSYS-Matlab model for large}

2 solar collector fields for district heating applications

\section{Federico Bava* and Simon Furbo}

4 DTU Civil Engineering, Technical University of Denmark, Brovej, Building 118, 2800 Kgs. Lyngby 5 (Denmark)

$6 \quad *$ Tel.: +45 45251700, Email: febav@byg.dtu.dk

\section{Abstract}

8 This study describes the development of a detailed TRNSYS-Matlab model to simulate the behavior of a 9 large solar collector field for district heating application. The model includes and investigates aspects which are not always considered by simpler models, such as flow distribution in the different rows, effect of the flow regime on the collector efficiency, thermal capacity of the components and effect of shadows from row to row. The model was compared with measurements from a solar collector field and the impact of each aspect was evaluated. A good agreement between model and measurements was found. The results showed that a better agreement was achieved, when a flow regime-dependent efficiency of the collector was used. Also the precise flow distribution in the collector field improved the model accuracy, but it must be assessed if the aimed level of accuracy justifies the much longer programming and computing time. Thermal capacity was worth being considered only for the bulkier components, such as the longer distribution and transmission pipes. The actual control strategy, which regulates the flow rates in the solar heating plant, was accurately reproduced in the model, as proved by the good agreement with the measurements.

Keywords: solar collector field; TRNSYS; simulation; flow regime; flow distribution.

Nomenclature

$a_{2} \quad$ temperature dependence of the heat loss coefficient of collector

$c_{p} \quad$ specific heat

DH district heating

$F_{f} \quad$ correction factor for heat exchanger fouling

$G_{\text {tot }} \quad$ hemispherical solar irradiance

$\dot{m} \quad$ mass flow rate

nom subscript referring to nominal conditions

$Q_{\text {sol }} \quad$ theoretical solar energy output from the collector field

Re Reynolds number

$R M S D$ root-mean-square deviation

$s_{i} \quad$ uncertainty of the function/variable $i$

$T_{m} \quad$ mean fluid temperature in the collector field

$T_{\text {amb }}$ ambient temperature

UA overall heat transfer coefficient of the heat exchanger

$\eta_{0} \quad$ peak collector efficiency

$\left[\mathrm{m}^{2}\right]$

$\left[\mathrm{W} \mathrm{m} \mathrm{K}^{-2} \mathrm{~K}^{-1}\right]$

$\left[\mathrm{W} \mathrm{m} \mathrm{m}^{-2} \mathrm{~K}^{-2}\right]$

$\left[\mathrm{J} \mathrm{kg}^{-1} \mathrm{~K}^{-1}\right]$

$[-]$

[W m $\left.\mathrm{W}^{-2}\right]$

$\left[\mathrm{kg} \mathrm{s}^{-1}\right]$

[W]

$[-]$

$\left[{ }^{\circ} \mathrm{C}\right]$

$\left[{ }^{\circ} \mathrm{C}\right]$

$\left[\mathrm{W} \mathrm{K}^{-1}\right]$

$[-]$

\section{Introduction}

\subsection{Background}

41 To reach the $\mathrm{CO}_{2}$-reduction goals agreed at the COP21 conference in Paris, reduce energy imports and cut costs for households and businesses, the European Union will act on several fronts. Among these, a key role should be played by the spread of district heating (DH) and the integration of renewable energy sources into DH networks (European Commission, 2016). 
economically provide energy at the temperature levels required by these applications, they seem a perfect candidate to cover this demand. Although solar heating systems are fairly common in the single-family house sector, large solar thermal plants for DH are still rare, except for a few countries, and represented less than

$501 \%$ of the total installed water collector capacity at the end of 2016 (Weiss et al., 2017). Approximately $515000 \mathrm{DH}$ networks are currently in operation in Europe, supplying $10 \%$ of the total heat demand (AEBIOM, 52 2012). Of these, about 300 are solar assisted DH systems at the end of 2016 (Weiss et al., 2017). However, 53 the contribution of solar energy to DH in Europe is expected to increase. According to the SDHtake-off 54 project, supported EC-Programme IEE Intelligent Energy Europe, a solar fraction of $1 \%$ by 2020 and of $5 \%$ 55 by 2050 is realistic (Schubert et al., 2010; SDHtake-off, 2012).

56 Although several large solar plants for DH have been installed in Germany, Austria and Sweden (Schubert et 57 al., 2010), Denmark is still the main market for this technology, with $79 \%$ of the total collector area installed in Europe at the end of 2016 (Weiss et al., 2017). In the Scandinavian country some specific factors, such as high taxation on fossil fuels and widespread use of DH, has lead this development (Furbo et al., 2015). At the end of 2016, Denmark had more than 1,300,000 $\mathrm{m}^{2}$ of solar collector fields (Trier, 2016). Additionally, the size of the collector fields has been constantly increasing and at the end of 2016 a 156,000 $\mathrm{m}^{2}$ collector field was completed in Silkeborg (Rasmussen, 2016). An even larger installation may come about in the next years, if the project for a 450,000 $\mathrm{m}^{2}$ collector field is realized in Graz, Austria (Reiter et al., 2016).

In a scenario where solar collector fields become increasingly larger and supply increasingly higher solar fractions, even small performance improvements in relative terms can lead to a large increase in the overall energy production in absolute terms. Hence, it is important to be able to predict the behavior and performance of these plants in the most accurate way. If correct sizing, control strategy and design improvements can be accurately evaluated in advance and implemented already in the planning phase, later and more expensive interventions can be avoided. Additionally, detailed simulation models can be used for on-line simulations, which use real-time measured data as input (Perers and Furbo, 2014), to continuously monitor the plant and verify whether this meets the expected performance.

So, the aim of this study was to develop a detailed simulation model of a large solar collector field for DH application. The model was developed in TRNSYS-Matlab. The model treated aspects which are usually neglected in simpler models, such as flow distribution, collector efficiency dependence on the flow regime, etc., in order to evaluate their impact on the overall model accuracy. The reliability of the model was verified by comparing its results against experimental measurements.

The paper is structured as follows. Section 1.2 presents a literature review on modeling of solar heating systems and the challenges that were addressed in this study. Section 2 describes the collector field used for the model validation and the developed TRNSYS model. Section 3 presents and analyzes the results of the TRNSYS subsystems used to calibrate single model components, as well as the comparison between the results of the model of the solar heating plant and the measurements. The titles of the subsections of Sections 2 and 3 are almost identical, so that for each component the reader can easily move from the methodology subsection to the corresponding result and discussion subsection. Section 4 summarizes the main conclusions.

\subsection{Literature review}

86 Le Denn (2014) distinguishes the available simulation tools for large solar collector fields for DH 87 applications in two categories. The first category includes dedicated solar DH tools, such as F-Easy (Nielsen 88 and Battisti, 2012), Fjernsol-II (PlanEnergi, 2013), SDH Online-Calculator (Deschaintre, 2014) and Sunstore 894 Tool (CIT Energy Management, 2013). The second category includes generic software, such as TRNSYS 90 (Klein et al., 2012), energyPRO (EMD International A/S, 2016), Polysun (Vela Solaris, 2016) and 91 RETScreen (Natural Resources Canada, 2016).

The programs of the first category are mainly feasibility tools, suitable for rough estimation of the system performance on yearly or monthly basis. They are simple to use, but offer limited detail and few possibilities of customization, so they were discarded for this study. Of the second category, TRNSYS was identified as the most suitable simulation program, as it offered different advantages compared to the other tools. First of all, TRNSYS comes with a wide library of validated component models. Besides the original TRNSYS component library, other libraries (Schwarzbözl, 2007; TESS, 2012) or single components have been 
developed by different institutions or programmers. Additionally, TRNSYS users can write and compile their

99 own components, or customize existing ones by editing their source code. Finally, TRNSYS can interact 100 with other software, such as Matlab, while a simulation is running. All these possibilities give a high 101 flexibility in the use of the software, which was hence chosen for this study.

102 TRNSYS has been widely used for simulation of solar thermal systems. Numerous articles report on studies 103 where TRNSYS was successfully used to simulate domestic or small case solar thermal systems. A selection 104 of these is presented in the review by Saleem et al. (2015). Larger parabolic trough collector fields connected 105 to power plants have been modeled in TRNSYS (Abdel Dayem et al., 2014; Biencinto et al., 2016, 2014). In 106 the field of solar DH, Raab et al. (2005) developed and validated a TRNSYS model to simulate the solar 107 assisted DH system in Hannover. Sibbitt et al. (2012) used TRNSYS in the design phase of the solar DH 108 system of Drake Landing Solar Community in Canada. The monitored data of the installed system were in 109 satisfactory agreement with the model. Bava et al. (2015) modeled a single collector row in the collector 110 field by Brædstrup II, Denmark. The comparison between simulation results and measurements shows that 111 inaccurate solar radiation measurements and decreased collector efficiency (caused for example by dirty 112 glass cover) may compromise the agreement between model and monitored data.

113 In most of the mentioned studies, the collector field was only a part of the entire system and hence was 114 treated with little detail, usually by a single collector component. Consequently, aspects such as flow 115 distribution across the collector field are not considered, although they may have an impact on the collector 116 field performance (Dorantes et al., 2014). This is especially valid nowadays, when the collector fields have 117 become increasingly larger. Additionally, modeling the entire collector field as a single component entails 118 that also the distribution pipes in the model do not have the actual layout or fluid content. This can easily 119 lead to an advance or delay of the model response compared to reality. To address this problem, the 120 TRNSYS model developed in this study was made interact with a previously validated Matlab model (Bava 121 et al., 2017), so to accurately take into account the exact flow distribution across the collector field (see 122 Section 2.2.2.2).

123 Another simplification consists of assuming the collector efficiency expression constant. Among the 124 different operating conditions which can affect the collector efficiency, the flow regime in the absorber pipes 125 has great importance (Bava and Furbo, 2014; Hausner and Fechner, 1998). Most collectors are tested using 126 water as heat transfer fluid and in condition of turbulent flow. If the collector is supplied with propylene 127 glycol/water mixtures, laminar regime may take place, reducing its efficiency. Therefore, using the 128 certificate collector efficiency as input to the model is likely to cause an overestimation of the collector 129 performance compared to real-world operation. To reproduce the behavior of the collectors in a more 130 realistic way, the collector efficiency from the collector test report was corrected to take into account the 131 different heat transfer fluid through a collector simulation program. Additionally, a new TRNSYS collector 132 component was developed, to account for the effect of the flow regime on the collector efficiency.

133 Other aspects which are often neglected for sake of simplicity, but which were considered in this study, are 134 thermal capacity of pipes, distinction between beam and diffuse radiation and shadow effect from one row to 135 another.

\section{2. Material and method}

137 This section describes the solar collector field used for the model validation and the TRNSYS model itself. 138 The collector field is described in terms of hydraulic layout, system components, measuring equipment and 139 control strategy. Regarding the TRNSYS model, the list of utilized components as well as the reasons and 140 considerations behind their choice are presented.

\subsection{Description of the solar collector field}

\subsubsection{Collector field design}

143 The TRNSYS model presented in this paper was developed based on the solar collector field near Høje Taastrup, Denmark (Figure 1). As can be seen from the layout in Figure 2, the collector field consisted of two subfields, having 12 collector rows each. Each row was composed of 10 HTHEATStore 35/08 collectors (SP, 2016) from the company Arcon-Sunmark A/S. The collectors were harp flat plate collectors with 18 
horizontal absorber pipes and a gross area of $13.57 \mathrm{~m}^{2}$. The collector field gross area was $3257 \mathrm{~m}^{2}$. The

148 declared collector efficiency is reported in Table 1. The row distance was $5.5 \mathrm{~m}$. The collector tilt angle was $14943^{\circ}$ and the orientation $2.5^{\circ} \mathrm{W}$. The solar collector fluid was a $35 \%$ propylene glycol/water mixture (Bava et 150 al., 2017). Normal operating temperatures for the collector field were of $50-55{ }^{\circ} \mathrm{C}$ in inlet and $90-95{ }^{\circ} \mathrm{C}$ in 151 outlet. The flow rate ranged from 8 to $50 \mathrm{~m}^{3} \mathrm{~h}^{-1}\left(0.04-0.26\right.$ liter $\left.\mathrm{min}^{-1} \mathrm{~m}^{-2}\right)$ depending on the solar irradiance.

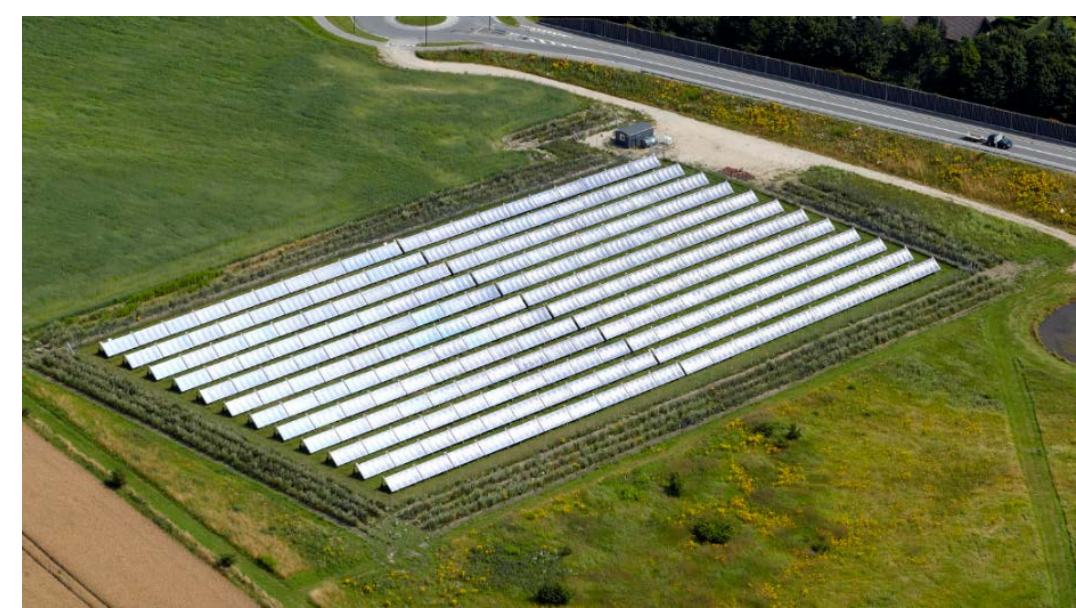

Figure 1: Aerial picture of Høje Taastrup solar collector field (source: Arcon-Sunmark A/S).

154 Both supply and return pipes of the primary loop (or solar collector loop) were made of preinsulated steel 155 pipes (Logstor, 2005) with progressively decreasing diameter, as part of the flow was diverted to the 156 collector rows. As seen in Figure 2, supply pipes (in blue) supplied the collector rows from the outer sides of 157 the collector field, while a single return pipe (in red) collected the heated fluid in the middle of the field. 158 Balancing valves were installed and regulated at the inlet of each collector row, to guarantee a uniform flow 159 distribution across the collector field (Bava et al., 2017).

160 The technical building (top-right corner in Figure 2) hosted pumps, expansion vessels, control system, 161 measuring equipment and the plate heat exchanger, which connected primary and secondary side.

162 The secondary side was connected to the DH main network through $550 \mathrm{~m}$ long transmission pipes. To avoid 163 supplying too cold fluid to the network in the start-up phase, a bypass is installed at the end of the 164 transmission pipes and it is used to recirculate the fluid until a temperature of at least $65^{\circ} \mathrm{C}$, compatible with 165 the DH network, is reached. 


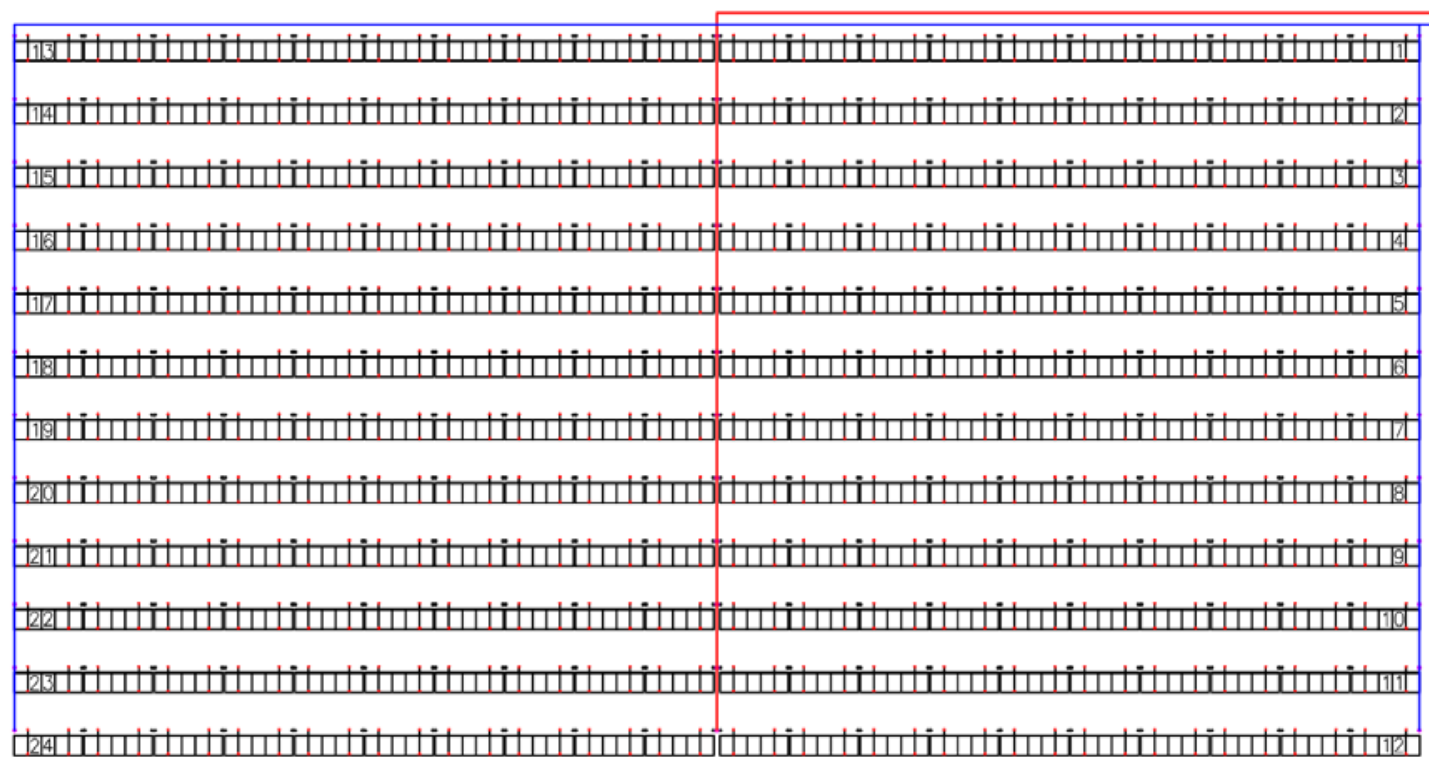

Figure 2: Layout of Høje Taastrup solar collector field: blue and red lines represent supply and return pipes respectively (adapted from Arcon-Sunmark A/S).

\subsubsection{Measuring equipment}

Electromagnetic flow meters with an accuracy of $\pm 0.5 \%$ measured the volume flow rate in both primary and secondary side. The temperature of the heat transfer fluids was measured by resistance thermometers with an accuracy of $0.25 \mathrm{~K}$. The temperature was monitored at the beginning of the supply pipe, at the end of the return pipe, at the inlet and outlet of collector rows 1, 11, 13 and 23 (Figure 2), at each inlet and outlet of the heat exchanger, and at the end of the transmission pipes. The ambient temperature in the field was measured too.

The solar irradiance on the collector field was measured by pyranometers in different parts of the collector field. Three photovoltaic cell pyranometers (SolData, 2016) were installed next to one another in the collector field and used in the control strategy. However, this kind of sensors is known to degrade over time, underestimating the actual solar irradiance. For this reason, four Kipp \& Zonen thermopile pyranometers were added. A secondary standard CMP11 pyranometer and a first class CM5 pyranometer equipped with shadow ring were placed in the middle of the collector field on top of a collector, to measure the total and diffuse irradiance on the collector plane. The diffuse irradiance was corrected to account for the shadow ring using Drummond's (1956) model. From the total and the diffuse irradiance, the beam component was determined. Other two secondary standard CM11 pyranometers were placed at the north-east and north-west corner of the collector field to measure possible differences between morning and afternoon incident radiation due to reflection from the collectors.

The instantaneous values of the monitored data were recorded once per minute. The sampling time used for control purposes was on the other hand much shorter $(<1 \mathrm{~s})$.

\subsection{Description of the TRNSYS model}

TRNSYS is a transient system simulation tool having a modular structure. A TRNSYS project is set up by interconnecting different modules, which build up the system which is to be simulated. The following sections explain which components built up the model, why they were chosen and how they were connected. A detail of the overall TRNSYS model of Høje Taastrup collector field is shown in Figure 3. Simpler models were developed to calibrate single components, as described in the following sections.

Perers and Furbo (2014) identify several aspects which should be taken into account, to develop accurate simulation models for large solar collector fields. These range from accurate weather data to choice of the component models, from flow distribution across the collector field to thermal capacity of the components. So the following sections also describe how these different aspects were addressed in this study. 
Accurate weather data, including the distinction between beam and diffuse irradiance on the collector plane, should be used as input (Perers and Furbo, 2014). Both solar irradiance and ambient temperature were measured in the collector field by high class thermopile pyranometers (see Section 2.1.2). The measured weather data, as well as all other relevant monitored data from Høje Taastrup collector field, were loaded into the TRNSYS model by the data reader Type 9c (Klein et al., 2012).

To simulate the collector array shading, Type 30 (Klein et al., 2012) was used. The so corrected diffuse and beam irradiances were input to all collector rows except the front ones, which were not shaded.

According to Perers and Furbo (2014), the time resolution is also very important. Usually hourly mean values are available, but higher time resolution is desirable to test control algorithms. Hence, all recorded data (one minute time step) were used without averaging.

\subsubsection{Model components}

211 Regarding the components models, Perers and Furbo (2014) suggest using already validated models instead

212 of detailed theoretical components, to save both programming and computing time. Hence, almost all

213 components used in the simulation model were taken from existing and well-established TRNSYS libraries

214 (Klein et al., 2012; Schwarzbözl, 2007; TESS, 2012).

\subsubsection{Collector type components}

A collector model which is compatible with the collector test standard ISO 9806 (ISO, 2014) should be used (Perers and Furbo, 2014). To be able to consider aspects which are usually neglected when simulating solar collector fields, Type 330 was used. This is an in-house model developed by editing Type 539 (TESS, 2012) with some desired features added. First of all, Type 330 makes use of a different efficiency expression depending on the flow regime in each node in which the collector is divided. Consequently, this collector type requires two efficiency expressions, one for laminar and one for turbulent regime. This may be a problem, as collector certificates provide only one efficiency expression, usually for turbulent conditions. In this study, a simulation model of the investigated collector HTHEATStore 35/08 (SP, 2016) was developed with the software Soleff (Rasmussen and Svendsen, 1996), based on the collector design and the operating conditions used during the efficiency test. The good agreement between the certificate efficiency and the simulated efficiency (RMSD $=0.12 \%$ ) proved the reliability of the Soleff model. The model was then used to calculate the collector efficiency in laminar and turbulent conditions for a $35 \%$ glycol/water mixture. The coefficients of the declared and simulated efficiencies are listed in Table 1.

Table 1: Declared and simulated efficiencies of HTHEATStore 35/08 collector based on the gross area of $13.57 \mathrm{~m}^{2}$.

\begin{tabular}{|c|c|c|c|c|}
\hline & Fluid & $\eta_{0}[-]$ & $\mathrm{a}_{1}\left[\mathrm{~W} \mathrm{\textrm {m } ^ { - 2 } \mathrm { K } ^ { - 1 } ]}\right.$ & $\mathrm{a}_{2}\left[\mathrm{~W} \mathrm{\textrm {m } ^ { - 2 } \mathrm { K } ^ { - 2 } ]}\right.$ \\
\hline Declared efficiency (SP, 2016) & water & 0.757 & 2.199 & 0.007 \\
\hline Soleff efficiency (test conditions) & water & 0.757 & 2.260 & 0.006 \\
\hline Soleff efficiency (turbulent) & 35 \% glycol & 0.756 & 2.318 & 0.006 \\
\hline Soleff efficiency (laminar) & 35 \% glycol & 0.727 & 2.357 & 0.005 \\
\hline
\end{tabular}

231 Considering the operating conditions in Høje Taastrup collector field (see Section 2.1.1) and assuming $232 R e=2300$ as threshold between laminar and turbulent flow, about one third of the collectors experienced 233 laminar flow. For this reason, it was relevant to have a different efficiency expression in case of laminar 234 flow.

235 A second feature of Type 330 is the possibility for the user to specify an incidence angle modifier (IAM) for 236 diffuse radiation, instead of having it internally calculated as in Type 539. Another feature consists of the 237 wider range of incidence angle where the IAM-expression for beam radiation is used. The range is chosen 238 depending on the data available in the technical datasheet of the collector which is to be simulated. The 239 original Type 539 linearizes the IAM for angles between $60^{\circ}$ and $90^{\circ}$.

240 To evaluate whether the improvements introduced in Type 330 had an effect, three different collector type 241 variants were analyzed. The first used Type 539 and the declared collector efficiency (Table 1). The second 
made use of Type 330 and the Soleff efficiency equation for turbulent conditions (Table 1), regardless of the actual flow regime in the absorber pipes of the collectors. In the third variant, all features of Type 330 were enabled. For sake of simplicity, the first and second variants of Type 330 are referred to as Type330a and Type330b in the rest of the paper. To focus on the behavior of the different collector variants and avoid the influence of external factors, such as control strategy and secondary side temperatures, only the primary side of the collector field was modeled, and the measured flow rate, collector field supply temperature and weather data were given as input. The modeled return temperatures from the collector field in the three scenarios were compared to the measurements. Different types of weather conditions were considered: clear sky, cloudy sky with fluctuating solar radiation and overcast sky.

\subsubsection{Flow distribution}

To take into account the flow distribution in the collector field, each single collector row was modeled. As TRNSYS cannot solve problems of flow distribution in hydraulic networks, Type 155 (Klein and et al., 2012) passed the necessary inputs to a Matlab program (Bava et al., 2017). Matlab evaluated the flow distribution in the different collector rows and returned the result to TRNSYS, where the total flow was then distributed to the different rows accordingly.

To evaluate the impact of modeling the exact flow distribution, the detailed model using Type 330b (Section 2.2.2.1) was compared to a simpler model. The simpler model differed from the detailed one, as the entire collector array was simulated through a single Type330b. Additionally, the supply and return pipes were modeled by a pipe component each (see Section 2.2.2.3). The pipe length used as input in the pipe components was the average distance between the technical building and each collector row. The thermal capacity of the pipes was proportionally scaled (see Section 2.2.2.3).

\subsubsection{Pipes and heat exchanger}

Type 709 (TESS, 2012) was chosen to model the distribution pipes, as it had a better agreement with the measurements, compared to Type 31 (Klein et al., 2012) and Type 604 (TESS, 2012). However, unlike Type 604, Type 709 does not consider the thermal mass of the pipe material, which may be relevant, especially in case of long transmission pipes. To take this aspect into account and evaluate its impact on the accuracy of the model, the thermal capacity Type 306 (Schwarzbözl, 2007) was added to the longest distribution and transmission pipes. Specific TRNSYS projects were built, simulating only the investigated pipes. In this way, all the other simplifications of the model, which could have an effect on the simulation results, were excluded. The pipes investigated in detail were the supply pipe to the western subfield (see Figure 2 and Figure 3) and the transmission pipe from the heat exchanger to the DH network (see Section 2.1.1 and Figure 3). These were chosen because their inlet and outlet temperatures were monitored. Additionally, the flow rate in the transmission pipe was directly measured, while the flow rate in the western supply pipe could be estimated based on the measured primary flow rate and the flow distribution model (Section 2.2.2.2). Pipe dimensions and material properties were also known. Finally, these pipes had the largest thermal mass, so they were the most relevant to investigate with respect to thermal inertia effect. The model used the measured inlet temperature and flow rate as input, and the resulting outlet temperatures were compared with the measured.

To accurately model the plug flow along the pipes, all distribution pipes segments were simulated, as well as connection hoses between consecutive collectors (Type 31 in Figure 3). This also allowed taking into account the heat losses from the connection hoses. The soil temperature to calculate the heat losses from the buried pipes was evaluated through Type 77 (Klein and et al., 2012).

The plate heat exchanger between the solar collector loop (primary side) and the DH network (secondary side) was modeled through Type 5b (Klein et al., 2012). This type offers the possibility of inserting a variable heat transfer coefficient. A specific TRNSYS project, simulating only the heat was developed to calibrate Type $5 \mathrm{~b}$ against measurements. Measured flow rates and inlet temperatures were given as input to Type $5 \mathrm{~b}$ and the heat transfer coefficient was varied so to obtain the best agreement between measured and modeled outlet temperatures.

\subsubsection{Control strategy}

291 The control strategy implemented in the model was based on the information received by the plant designer 
Arcon-Sunmark A/S. The control strategy aimed at reaching a constant outlet temperature, by continuously regulating the total flow rate based on the solar irradiance. The desired outlet temperature is the DH supply temperature, increased by the temperature drop across the heat exchanger. As the collector field was not located near an auxiliary energy source, the collector field outlet temperature must meet the DH requirements, if the energy is to be delivered to the DH network.

297 The main principles of the control strategy in Høje Taastrup solar heating plant can be summarized as 298 follows. The relation (Eq. 1) gives the theoretical solar energy output $Q_{s o l}$, which is then used to regulate the 299 primary pump flow rate (Eq. 2). The primary pump is denoted as Pump 1 in Figure 3.

$$
Q_{\text {sol }}=A_{\text {field }}\left(G_{\text {tot }} \eta_{0}-a_{1} \cdot\left(T_{m}-T_{a m b}\right)-a_{2} \cdot\left(T_{m}-T_{a m b}\right)^{2}\right)
$$

$\dot{m}=\max \left[\dot{m}_{\text {min }}, Q_{\text {sol }} /\left(c_{p} \cdot\left(T_{\text {out }, \text { setpoint }}-T_{\text {in }}\right)\right)\right]$

$302 T_{m}$ is the mean temperature between the measured collector field inlet temperature $T_{\text {in }}$ and the desired outlet 303 temperature $T_{\text {out,setpoint }}$. The solar irradiance $G_{\text {tot }}$ is measured by the photovoltaic cell pyranometers (see 304 Section 2.1.2).

305 The condition for the primary pump to turn on is that either $Q_{s o l}$ is higher than a certain threshold, or one of the monitored fluid temperatures in the collector field is higher than a preset value. The turn-off condition is the negation of the turn-on condition, delayed by the time needed to discharge the energy content of the hot return pipes. Because at the start-up of the primary pump in the morning the primary loop is still relatively cold, the flow bypasses the heat exchanger and is recirculated across the collector field (Bypass1 in Figure 3 ). When the field outlet temperature is sufficiently high, the primary bypass is closed and the secondary pump is turned on. The secondary pump is regulated so that the heat capacity rate on both sides of the heat exchanger is the same. At the start-up of the secondary pump, the bypass installed at the end of the transmission pipes (Bypass2 in Figure 3) recirculates the fluid until a temperature of $65{ }^{\circ} \mathrm{C}$, compatible with 314 the DH network, is reached.

315 In the TRNSYS model, most of the control strategy is implemented in an Equation block, while the turn316 on/off conditions and the time delay are set by a differential controller Type 2d and Type 93 respectively 317 (Klein and et al., 2012).

318 A detail of the overall TRNSYS model, which implemented also the control strategy of the solar heating 319 plant, is shown in Figure 3. The only measured values used as input were the weather conditions (irradiance and ambient temperature) and the return temperature from the DH network. The accuracy of the model was tested, by comparing simulated and measured temperatures, energy outputs and flow rates under different weather conditions. 


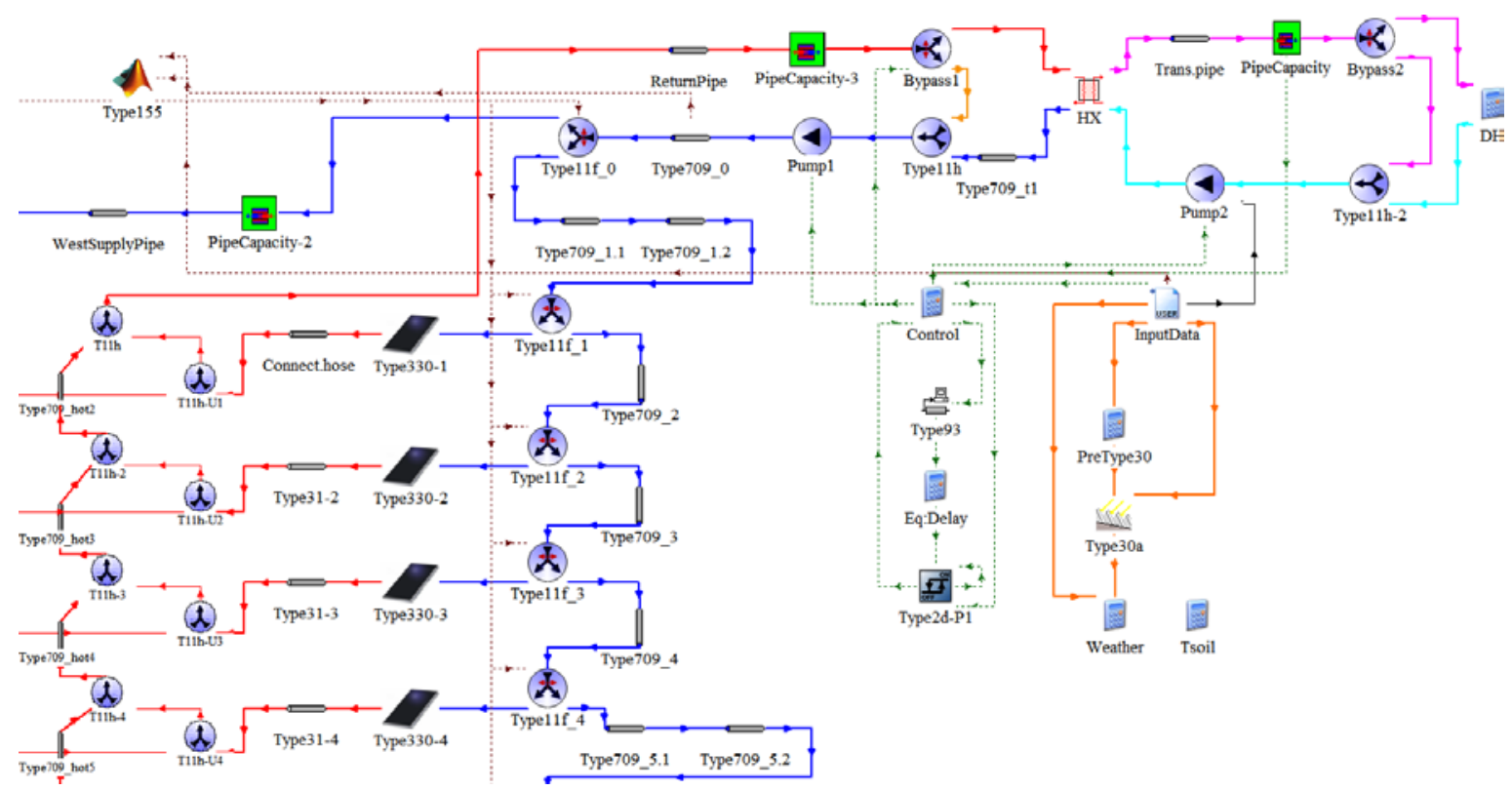

Figure 3: Detail of the TRNSYS model of Høje Taastrup solar heating plant. For sake of clarity, only the first four collector rows of the eastern subfield are shown. Blue and red connections represent the supply and return pipes of the solar collector glycol loop; purple and pale blue connections represent the supply and the return pipes with water to/from the DH network.

\section{Results and discussion}

This section presents and analyzes the results from the validation of the single components or subsystems, such as solar radiation sensors, solar collector, heat exchanger and pipes. Based on these results, the parameters of the single components could be accurately determined and used in the model of the solar heating plant. Secondly, the validation of the model of the plant is presented.

\subsection{Solar radiation measurements}

Figure 4 shows the relative difference between the total solar irradiance measured by the photovoltaic cell pyranometers and that from the thermopile CMP11 pyranometer in a clear sky day. It can be seen that for high irradiances $\left(G_{t o t}>800 \mathrm{~W} \mathrm{~m}^{-2}\right)$, the photovoltaic pyranometers underestimated the solar irradiance by 7$8 \%$. At lower irradiances (and larger incidence angles) the difference increased, up to $27 \%$ for $G_{\text {tot }}=200 \mathrm{~W}$ $\mathrm{m}^{-2}$. The non-perfect overlap of morning and afternoon data must have been caused by a small difference in the orientation of the pyranometers, with the CMP11 sensor oriented slightly more eastward than the photovoltaic sensors.

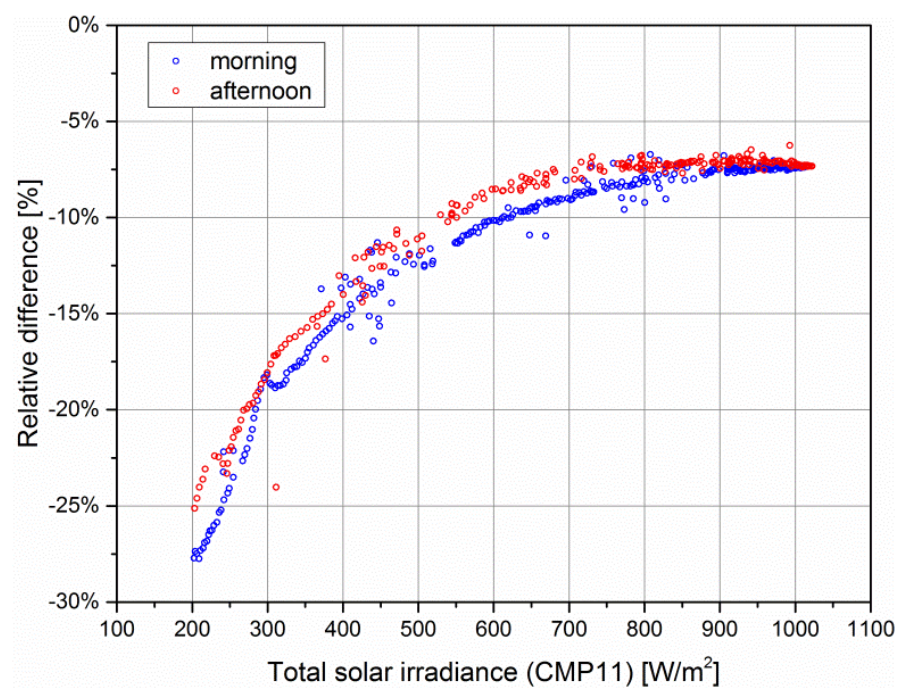


343 As all sensors had been recently cleaned, the difference in the reading cannot be attributed to soiling, but was 344 likely caused by degradation of the photovoltaic cell. Repeated measurements in similar sky conditions gave 345 similar results. Conversely, lower differences $(\leq 5 \%)$ were found in case of overcast sky. This led to the 346 conclusion that the large deviations between photovoltaic and thermopile pyranometer in the early morning and late afternoon were caused by larger incidence angles rather than low solar radiations.

348 The significant decrease in sensitivity of the photovoltaic pyranometer over time is a problem which is often 349 observed with this type of sensors. However, photovoltaic cell sensors have the advantage of much lower 350 price and much shorter response time (some milliseconds (SolData, 2016)), compared to a thermopile sensor 351 (5-20 seconds (Kipp \& Zonen, 2006)). If the instantaneous measured solar irradiance is used for control 352 purposes, a fast response time of the sensor is of key importance and photovoltaic cell sensors could be 353 preferred. However, they should be regularly checked and their sensitivity corrected, if needed. Additionally, 354 the strong directional response (i.e., dependence of the measured radiation on the incidence angle) of the 355 photovoltaic pyranometer suggests introducing a second correction to account for this effect.

356 Given the significant difference between the solar irradiance measured by the photovoltaic cell pyranometers 357 and that from the thermopile pyranometers, it was important to use the two of them properly. Hence, the 358 irradiance measured by the photovoltaic cell was used in the control strategy of the model, as it was used in 359 the actual solar heating plant. The irradiance measured by the thermopile pyranometers provided the weather 360 data input to the collector TRNSYS types.

\subsection{Collector type components}

362 With all three collector type variants, the collector field return temperature calculated by the model was always higher than the measured, if the efficiencies listed in Table 1 were used. To have a good agreement between the two, the peak collector efficiency $\eta_{0}$ had to be reduced by $7.3 \%$ for Type 330b and Type 539, and by $7.8 \%$ for Type 330a. For each type variant, the exact reduction was chosen so that the modeled daily energy output from the collector field differed from the measured one less than $\pm 1 \%$.

The good accuracy of the measurement equipment (Section 2.1.2) excluded the presence of faults in the measured data used as input for the model. Additionally, these data were also carefully checked to spot possible outliers. Secondly, the presence of temperature sensors at the inlet and outlet of some collector rows allowed having a clear focus on the behavior of the single rows. This excluded the influence of possible biased heat losses and plug flow in the pipes. In each modeled collector row, the only components were the collector (Type 539 or 330) and the pipe Type 31, to take into account plug flow and heat losses in the connection hoses. Hence, it was concluded that the disagreement between modeled and measured outlet temperature was most likely due to a difference between the actual collector efficiency and the efficiency from Soleff, based on the test report. As the variation of the heat loss coefficients (for example, due to moist insulation) could not be evaluated, the reduction in performance was entirely attributed to the decreased transmittance of the glass cover, which can be caused by soiling, dirt and moisture on the glass cover. The pollution from the motorway running just $150 \mathrm{~m}$ away might have a more negative effect than less trafficcongested areas.

Table 2 shows the RMSD between measured and modeled temperatures at the end of the return pipe from the solar collector field. If ranked in order of better agreement with the measurements, the three collector types were Type 330b, Type 539 and Type 330a.

Table 2: RMSD (in Kelvin) between measured and modeled return temperatures from the collector field with different collector type models.

\begin{tabular}{llccc}
\hline Date & Weather & Type 539 & Type 330a & Type 330b \\
\hline $12 / 07 / 2015$ & overcast & 2.05 & 1.99 & 1.74 \\
$13 / 07 / 2015$ & cloudy & 2.26 & 2.07 & 2.05 \\
$14 / 07 / 2015$ & sunny & 1.43 & 1.48 & 1.30 \\
$16 / 07 / 2015$ & sunny & 1.13 & 1.42 & 1.05 \\
$17 / 07 / 2015$ & cloudy & 1.71 & 1.95 & 1.72 \\
$24 / 07 / 2015$ & overcast & 1.99 & 2.24 & 1.75 \\
Mean & & 1.81 & 1.97 & 1.69 \\
\hline
\end{tabular}


386 So, the enhancements introduced in Type 330b improved the agreement between model and measurements, 387 compared to the original Type 539. However, Type 539 performed better than Type 330a. This can be 388 explained by the fact that the flow regime in the collector was laminar at low flow rates, which, according to 389 (Eq. 2), occurred in case of low solar irradiance. Low irradiance was measured either in the early morning 390 and late afternoon of clear sky days or in cloudy days. In these conditions, the overall IAM used by Type 539 391 was lower than that used by Type 330. In fact, in the early morning and late afternoon, at incidence angles 392 larger than $60^{\circ}$, Type 539 linearizes the IAM, which is hence lower than that calculated by Type 330 393 (Section 2.2.2.1). In cloudy conditions, when the fraction of diffuse radiation is significant, the IAM for 394 diffuse radiation calculated by Type 539 was lower than that used by Type 330 . Type 330 used a value of 395 0.94, as stated by the collector test report (SP, 2016). These two different effects (use of turbulent efficiency 396 also at low flow, and lower IAM at low radiation) almost canceled each other out in Type 539. 397 Consequently, this type was slightly less accurate than Type 330b. Conversely, Type 330a overestimated the collector efficiency in case of low flow and low irradiance, and hence had the least accurate agreement.

\section{3.3. Flow distribution}

400 According to the Matlab model, the flow distribution in the collector field was fairly uniform in all the tested conditions. The maximum relative difference between the modeled flow rate in a collector row and that in case of a perfectly uniform flow distribution was lower than $6 \%$. The maximum difference between highest and lowest row flow rates was lower than $10 \%$, which is the maximum deviation in flow distribution in solar collector arrays recommended by the German standard VDI (2004).

Because of the fairly uniform flow distribution, it could be expected that neglecting this aspect would not affect the agreement between model and measurements. To verify this hypothesis, a simpler model where the entire collector array was simulated by only one collector type was developed.

Table 3 lists the RMSDs between measured and modeled field return temperatures, both for the model taking into account the flow distribution and for the simpler model. As expected, the simpler model had higher deviations (by about $1 \mathrm{~K}$ ) compared to the more detailed model. Also in terms of energy output from the collector field, the simpler model differed more significantly from the measurements. Assuming the same decrease in the peak collector efficiency for both models $(-7.3 \%)$, the simpler model differed between $+0.5 \%$ and $+2.6 \%$, compared to $\pm 1 \%$ of the detailed model (Section 3.2 ).

Table 3: RMSD (in Kelvin) between measured and modeled return temperatures from the collector field in case flow distribution is modeled (Detailed model) or not (Simpler model).

\begin{tabular}{lcc}
\hline Date & Detailed model & Simpler model \\
\hline $12 / 07 / 2015$ & 1.74 & 2.94 \\
$13 / 07 / 2015$ & 2.05 & 2.77 \\
$14 / 07 / 2015$ & 1.30 & 2.06 \\
$16 / 07 / 2015$ & 1.05 & 2.10 \\
$17 / 07 / 2015$ & 1.72 & 2.65 \\
$24 / 07 / 2015$ & 1.75 & 1.97 \\
Mean & 1.69 & 2.44 \\
\hline
\end{tabular}

417 So taking into account the flow distribution improved the accuracy of the model compared to a perfectly 418 uniform flow distribution scenario. There are different reasons why the more detailed scenario gave a better agreement. Firstly, modeling each segment of the distribution pipes, instead of using an average pipe length, allowed reproducing accurately the plug flow along the pipes and hence the time delay that the fluid takes to reach the single collector rows. Considering this aspect improves the accuracy of the model mainly in terms of RMSD of the outlet temperature, as temperature fluctuations are in phase when comparing model and measurements. Secondly, if the flow distribution in the collector field is not uniform, this reduces slightly the energy output of the field, which the model is able to reproduce. Finally, if all pipe segments are modeled, the heat losses can be calculated more accurately. This aspect had however a limited impact, because being 
However, modeling the flow distribution was the most demanding and time consuming part, both in terms of programming and computing time. When TRNSYS used a time step of 1 minute, and convergence and integration relative tolerances of 0.001 , a simulation of 2 days of normal operation was performed in approximately 2.5 minutes by a computer with quad-core CPU, $2.4 \mathrm{GHz}$ CPU frequency and 8 GB memory. The computing time was about 4 times shorter, when Matlab was not called to calculate the flow distribution, and 50 times shorter for the simpler model, which used only one collector component to model the entire array. Therefore, the trade-off between increased accuracy and longer programming and computing time should be considered case by case. For example, a slower but more precise model could be desirable in case of on-line simulations. Conversely, a simpler but faster model is a better solution for preliminary evaluations 436 or feasibility studies.

\subsection{Pipes and thermal capacity}

438 The effect of thermal capacity was investigated adding Type 306 to the supply pipe to the western subfield and the transmission pipe from the heat exchanger to the DH network. Measured inlet temperature and flow rate were given as input to the model, and the model outlet temperatures were compared with the measured. Two different types of days were analyzed: July 14 and 16, mainly clear sky days; July 13 and 17, characterized by fast fluctuation in solar irradiance due to continuously moving clouds.

443

Table 4 lists the RMSDs between measured and modeled pipe outlet temperature of the investigated pipes. It should be noted that the listed values were obtained taking into account the thermal mass of the steel pipe only and neglecting that of the pipe insulation. This choice was motivated by the fact that this simplification had no or negative effect on the RMSDs. In fact, the thermal capacity of the insulation accounted only for $20 \%$ of that of the steel pipe. Additionally, because of its low thermal conductivity, only a portion of the insulation thermal mass would actually be involved in the dynamic response of the pipe. Finally, Type 306 models the thermal mass as a lumped capacity, characterized by one temperature and one heat transfer coefficient between fluid and solid part of the pipe. This simplification can be regarded as accurate for the steel pipe, due to its high thermal conductivity and small thickness, but not for the insulation.

Table 4: RMSD (in Kelvin) between measured and modeled pipe outlet temperatures with and without taking into account the thermal capacity (Cap.) of the steel pipe.

\begin{tabular}{lcccc}
\hline & $13 / 07 / 2015$ & $14 / 07 / 2015$ & $16 / 07 / 2015$ & $17 / 07 / 2015$ \\
\hline West supply pipe (no Cap.) & 1.87 & 1.67 & 1.93 & 3.12 \\
West supply pipe (with Cap.) & 1.15 & 1.20 & 1.45 & 1.91 \\
Transmission pipe (no Cap.) & 3.03 & 1.14 & 2.38 & 3.49 \\
Transmission pipe (with Cap.) & 2.19 & 1.05 & 0.71 & 1.48 \\
\hline
\end{tabular}

The remaining deviation between measured and modeled pipe outlet temperature could be caused by several factors, such as measurement accuracy and limitations of the model to reproduce the exact pipe conditions. Additionally, the measured data available, which were used as input for the model, were instantaneous values with recording time of one minute (Section 2.1.2). Hence, the pipe model assumed constant inlet temperature and flow rate over one minute, although this might not be necessarily the case, especially in conditions of fluctuating solar radiation and consequent fast variation of the pump speed (see also Section 3.6).

461 Because considering the thermal capacity of the pipes improved the agreement between model and 462 measurements, Type 306 was added to the longest pipes in the model, i.e. the western supply pipe, the common return pipe from the collector field and the transmission pipes to the DH.

\subsection{Heat exchanger}

465 A good agreement between modeled and measured outlet temperatures from the heat exchanger was found, if the overall heat transfer coefficient of Type $5 b$ was given by (Eq. 3).

$$
U A=F_{f}(U A)_{\text {nom }}\left(\frac{\dot{m}}{\dot{m}_{\text {nom }}}\right)^{0.6}
$$

468 According to the technical specifications of the heat exchanger, the heat transfer coefficient in nominal 469 conditions is $U A_{\text {nom }}=440 \mathrm{~kW} \mathrm{~K}{ }^{-1}$. However, to fit the model with the measured temperatures, it was 
necessary to introduce a correction factor for fouling $F_{f}=0.77$. A second correction was added to take into account the reduced convective heat transfer coefficient at flow rates lower than the nominal one, $\dot{m}_{\text {nom }}=58$ $\mathrm{m}^{3} \mathrm{~h}^{-1}$.

As the difference in heat transfer coefficient $U A$ between the technical specifications of the heat exchanger and real-world operation was significant, it was important to correct the model accordingly. Because flow rates and inlet/outlet temperatures across a heat exchanger are usually monitored, it is convenient to calibrate the heat exchanger model against measurements. For this purpose, one day of data with variable flow rate can be sufficient and improves the accuracy considerably.

Table 5: RMSD (in Kelvin) between measured and modeled outlet temperatures from the heat exchanger, with and without taking into account its thermal capacity (Cap.).

\begin{tabular}{lcccc}
\hline & $13 / 07 / 2015$ & $14 / 07 / 2015$ & $16 / 07 / 2015$ & $17 / 07 / 2015$ \\
\hline Outlet on primary side (no Cap.) & 1.39 & 0.64 & 0.53 & 1.24 \\
Outlet on primary side (with Cap.) & 1.38 & 0.63 & 0.53 & 1.23 \\
Outlet on secondary side (no Cap.) & 1.30 & 0.72 & 0.44 & 1.54 \\
Outlet on secondary side (with Cap.) & 1.15 & 0.69 & 0.47 & 1.52 \\
\hline
\end{tabular}

The heat exchanger outlet temperatures obtained by using (Eq. 3) were compared with the measurements from days with different sky conditions. The results are summarized in Table 5. The days July 14 and 16 were characterized by clear sky conditions and hence smooth variations of the flow rates, while July 13 and 17 had fast fluctuations of the flow rate due to passing clouds (see Figure 5). On the clear sky days, the RMSD between model and measured outlet temperatures was about $0.4-0.7 \mathrm{~K}$ on both primary and secondary side. On the cloudy days, characterized by rapidly varying flow rate, the RMSD was slightly higher (1.2-1.5 K). These larger deviations can be explained by the recording time of the measured data used as model input, as in Section 3.4. Adding the thermal capacity of both fluid content and metal plates to the heat exchanger through Type 306 had negligible effect on the RMSD in most cases, so this aspect was neglected in all other simulations.

\subsection{Control strategy and overall TRNSYS model}

The overall TRNSYS model reproduced in detail the solar heating plant in Høje Taastrup, both in terms of components and control strategy. The only external boundary conditions required by the model were the return temperature from the $\mathrm{DH}$ and weather conditions.

The good agreement between measurements and model can be appreciated in Figure 5. Figure 5 shows some of the measured and modeled data for two different types of weather conditions. As can be seen, July 13 was characterized by moving clouds and so fast fluctuations of the solar radiation, which caused higher deviations between measurements and model.

Table 6 presents an overview of the comparison between model and measurements in terms of fluid temperatures in different parts of the system, gross and net produced energy and flow rate in the primary side. The gross energy output from the collector field was calculated whenever the primary pump was in operation. So it also includes the energy collected during pre-heating of the primary loop, when the primary bypass was open. The energy delivered to the $\mathrm{DH}$ network was calculated at the end of the transmission line, when the supply temperature was higher than $65^{\circ} \mathrm{C}$ (Section 2.2.3). The cumulated flow is the time integral of the flow rate. The RMSD of the different temperatures is the deviation between measured and modeled values. Taking into account the accuracy of the measuring equipment (see Section 2.1.2) and the density and specific heat of the heat transfer fluids, the uncertainty of the measured energy outputs and cumulated flow rates was calculated through the formula for propagation of error (Eq. 4):

$s_{f}=\sqrt{\left(\frac{\partial f}{\partial x}\right)^{2} s_{x}^{2}+\left(\frac{\partial f}{\partial y}\right)^{2} s_{y}^{2}+\cdots+\left(\frac{\partial f}{\partial z}\right)^{2} s_{z}^{2}}$

510 where $s_{f}$ is uncertainty of the function $f$ (e.g., the energy output from the collector field) and $s_{i}$ is the uncertainty of the function variable $i$, (e.g., volume flow rate, density and specific heat of the fluid, inlet and outlet temperature). 


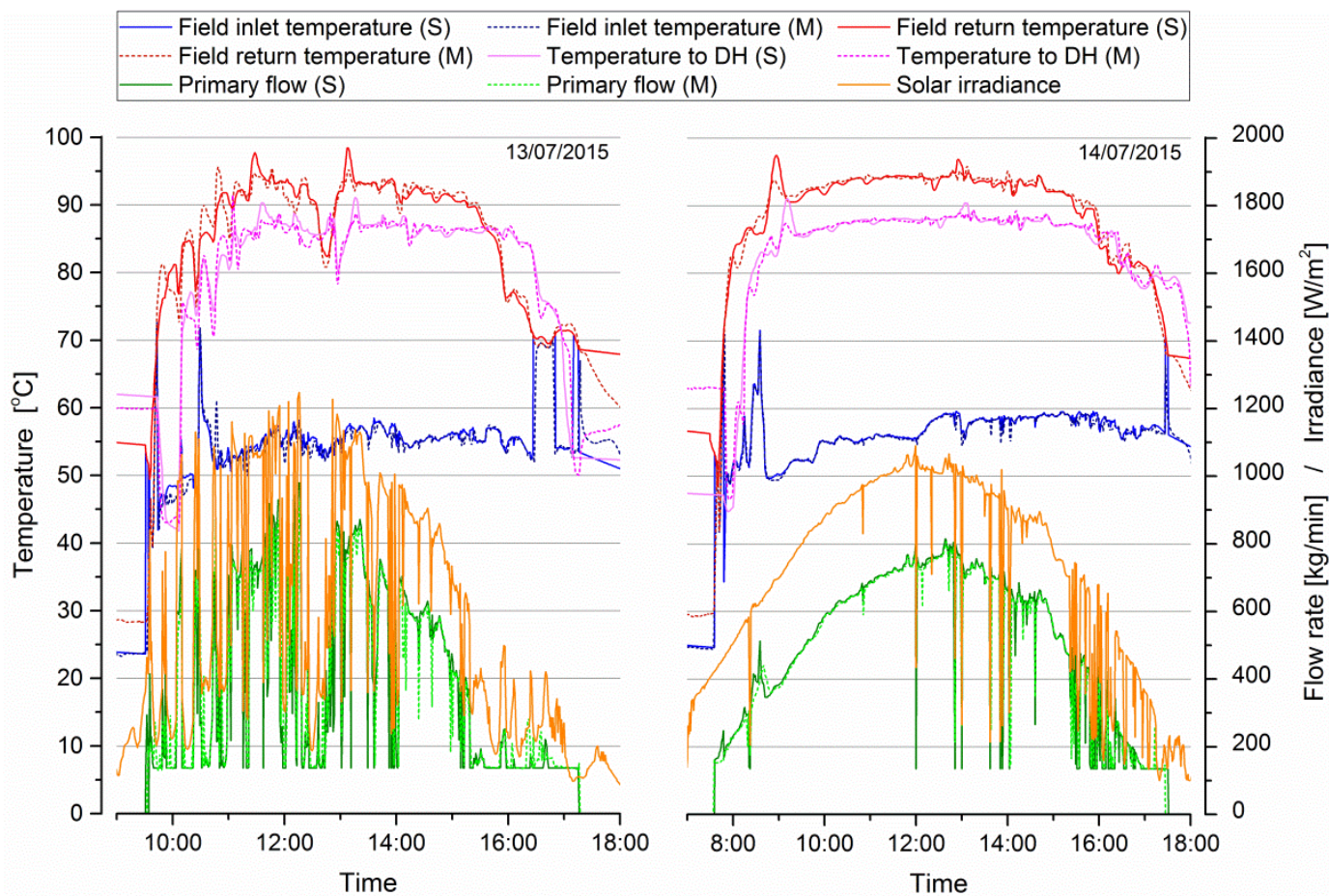

Figure 5: Comparison between measurements (M) and simulation results (S) based on the data from 13-14 July 2015.

518 The tabled values show the good agreement between model and measurements. In terms of energy and cumulated primary flow, the model differed from the measurements no more than $1 \%$, with the only exception being the overcast day July 12 .

Table 6: Comparison between measurements (M) and simulation results $(S)$ of the overall TRNSYS model.

\begin{tabular}{llrrrrr}
\hline & & $12 / 07 / 2015$ & $13 / 07 / 2015$ & $14 / 07 / 2015$ & $16 / 07 / 2015$ & $17 / 07 / 2015$ \\
\cline { 3 - 7 } Gross energy output from field (M) & MWh & 2.42 & 6.63 & 11.4 & 11.7 & 8.63 \\
Gross energy output from field (S) & MWh & 2.34 & 6.58 & 11.4 & 11.8 & 8.62 \\
Deviation in gross energy output & \% & $-3.3 \%$ & $-0.8 \%$ & $0 \%$ & $0.9 \%$ & $-0.1 \%$ \\
Energy supplied to DH (M) & MWh & 2.31 & 6.48 & 11.4 & 11.6 & 8.44 \\
Energy supplied to DH (S) & MWh & 2.27 & 6.47 & 11.3 & 11.7 & 8.45 \\
Deviation in energy to DH & $\%$ & $-1.7 \%$ & $-0.2 \%$ & $-0.9 \%$ & $0.9 \%$ & $0.1 \%$ \\
Cumulated primary flow (M) & $\mathrm{kg}$ & $8.24 \cdot 10^{4}$ & $1.79 \cdot 10^{5}$ & $2.92 \cdot 10^{5}$ & $2.99 \cdot 10^{5}$ & $2.29 \cdot 10^{5}$ \\
Cumulated primary flow (S) & $\mathrm{kg}$ & $8.03 \cdot 10^{4}$ & $1.78 \cdot 10^{5}$ & $2.95 \cdot 10^{5}$ & $3.02 \cdot 10^{5}$ & $2.29 \cdot 10^{5}$ \\
Deviation in primary flow & $\%$ & $-2.5 \%$ & $-0.6 \%$ & $1.0 \%$ & $1.0 \%$ & $0 \%$ \\
RMSD( $\left.T_{\text {supply to field }}\right)$ & $\mathrm{K}$ & 1.37 & 1.20 & 1.33 & 1.10 & 1.28 \\
RMSD $\left(T_{\text {return from field }}\right)$ & $\mathrm{K}$ & 2.82 & 2.37 & 1.48 & 1.76 & 2.59 \\
$\mathrm{RMSD}\left(T_{\text {supply to DH }}\right)$ & $\mathrm{K}$ & 3.77 & 2.20 & 1.43 & 1.89 & 2.29 \\
\hline
\end{tabular}

As expected, the temperature deviations were higher in the days characterized by fluctuating solar radiation (July 13 and 17), compared to clear sky days. The main reason for this is that, although both measured and simulated data were available once per minute, this one minute time step had a different meaning in the two cases. In the measured data, one minute is the recording time step, after which the instantaneous measured value of all monitored parameters was recorded. No information of what happened between one recording and the next was stored. In the simulation, one minute was the time step used by the model to calculate the 
such as flow rates, were assumed constant during the time step. This simplification is reasonable, when the input parameters change slowly, such as in clear or overcast sky conditions. Higher deviations can be expected, in case of higher frequency changes, for example in a cloudy day.

A second reason may be the different response time of the real pump and the pump model. The latter reacted instantly to a change in $Q_{\text {sol }}$ (Eq. 2), while the former had certain inertia. This effect was more evident in case of rapidly moving clouds and consequent fast variation of the pump speed.

Deviations in field return temperature were observed in the early morning, especially in presence of fluctuating solar radiation (Figure 5). On the other hand, July 14 (clear sky day) had a better agreement between measured and modeled temperature profiles, although some misalignment is still visible in the first hours of operation. This might be caused by the simplified modeling of the collector heat capacity. The current standard ISO 9806 (ISO, 2014) accounts for the collector heat capacity through a single value (the effective thermal capacity), which may not be sufficient to reproduce completely the dynamic response of the collector. Firstly, among the collector characteristic parameters determined by the quasi-dynamic test method (ISO, 2014), the effective thermal capacity may not always accurately be identified, due to the constant inlet temperature constraint, which limits the dynamic response of the collector (Kong et al., 2015). Secondly, because of how the test is performed, the calculated effective thermal capacity is affected by the residence time of the fluid in the collector, and hence may change at different flow rates. Additionally, the test method assumes a lumped heat capacity, without distinction between fluid and solid parts of the collector. However, it is reasonable to expect that the different components, such as fluid, metal parts and insulation, have a different dynamic response. Consequently, a value of effective thermal capacity, which may give a realistic response during normal operation, may not be as accurate in other phases, such as start-up and/or cooling down of the collector. However, the different effect of the collector thermal capacity between model and actual plant affected mainly the dynamic response of the collector field, and not its energy output. In fact the deviations between model and measured gross energy output in the morning only were not higher than $1 \%$.

The simulation results for July 12, day characterized by overcast sky conditions, had a lower agreement with the measurements compared to the other days. Both the simulated gross energy output from collector field and the simulated energy delivered to the DH network were lower than the measured ones $(-3.5 \%$ and $1.7 \%$ respectively). The main reason for this was found in the lower cumulated flow rate in the simulation compared to the measurements. The simulated and measured flow rates had extremely similar profiles, proving the good ability of the model control strategy to reproduce the actual one. However, the measured data showed some sudden and very brief peaks of the flow rates, which could not be reproduced by the model control strategy, because not justified by the recorded weather data. As mentioned above, the fact that the measured data are the instantaneous (and not average) values of the monitored data may explain part of the discrepancy. This explained also the higher RMSD of the investigated temperatures, as even temporary differences in flow rates immediately affect the plug flow, causing a shift and mismatch of the temperature profiles. Secondly, the gross energy production on this day was fairly low (2.42 MWh), between 2.7 and 4.8 times lower than the other investigated days. So, even modest absolute differences between model and measurements caused stronger relative differences, compared to days with higher energy output.

In Table 6 the data from July 24 are not shown. In fact, taking advantage of the overcast sky conditions, some manual calibration of the plant was performed in this occasion. Hence, the control strategy did not follow the equations described in Section 2.2.3, so it was pointless to compare the measured and modeled flow rate, and consequently all the other quantities.

\section{Conclusions and future perspective}

The developed TRNSYS-Matlab model showed a good agreement with the measurements in different weather conditions. Although the exact results presented in this study refer to the specific case of Høje Taastrup solar heating plant, they can be used to draw some general considerations and conclusions which should be taken into account when analyzing measurements from other solar heating plants or when modeling this kind of installations. The following conclusions can be drawn:

- Accuracy of the input data is of key importance for precise modeling. Special attention should be paid to solar radiation sensors, which should be recalibrated, if their sensitivity is suspected of 
varying.

- If the collectors experience laminar flow for a relevant fraction of their normal operating conditions, a collector model, such as Type 330, with efficiency equations defined differently depending on the flow regime, can improve the accuracy.

- Considering the exact flow distribution in the collector field improves the accuracy, but it requires much longer programming and computing time. Depending on the aimed level of accuracy, this aspect may be considered or not.

- The thermal capacity of pipes may be considered for longer pipes only, otherwise its role is negligible.

- The heat transfer coefficient of a heat exchanger should be estimated through measurements rather than from technical specifications, so to include aspects, such as fouling and flow rate dependence.

- It was possible to reproduce the actual control strategy of the solar heating plant, maintaining a good agreement between model results and measurements.

The presented model is meant to be used to investigate different improvements measures in terms of operating conditions and control strategies, which may enhance the performance of the plant and provide a more constant return temperature from the collector field. The improvements measured which are planned to be investigated are improvements of the control strategy (such as more detailed input and closed-loop control), different heat transfer fluids in the primary loop and different temperature levels. Additionally, one year simulations in the above mentioned conditions will elucidate their impact on the yearly performance.

\section{Acknowledgements}

The authors are thankful to the Marie-Curie Actions - Initial Training Network research programme of the European Union which supported the first author through the SolNet-SHINE project. The authors are also grateful to the company Arcon-Sunmark A/S and the DH company Høje Taastrup Fjernvarme for providing useful information necessary to develop the model and for granting access to the solar collector field in Høje Taastrup.

\section{References}

Abdel Dayem, A.M., Nabil Metwally, M., Alghamdi, A.S., Marzouk, E.M., 2014. Numerical simulation and experimental validation of integrated solar combined power plant. Energy Procedia 50, 290-305. doi:10.1016/j.egypro.2014.06.036

AEBIOM, 2012. EU Handbook - District Heating Markets [WWW Document]. URL http://www.crossborderbioenergy.eu/fileadmin/crossborder/DH_MarketHandbook.pdf (accessed 12.13.16).

Bava, F., Dragsted, J., Furbo, S., 2017. A numerical model to evaluate the flow distribution in large solar collector fields in different operating conditions. Sol. Energy 143, 31-42. doi:10.1016/j.solener.2016.12.029

Bava, F., Furbo, S., 2014. Comparative test of two large solar collectors for solar field application, in: Proceedings of EuroSun 2014 Conference. Aix-les-Bains, France. doi:doi:10.18086/eurosun.2014.16.03

Bava, F., Furbo, S., Perers, B., 2015. Simulation of a Solar Collector Array Consisting of two Types of Solar Collectors, with and Without Convection Barrier. Energy Procedia 70, 4-12. doi:10.1016/j.egypro.2015.02.091

Biencinto, M., Bayón, R., Rojas, E., González, L., 2014. Simulation and assessment of operation strategies for solar thermal power plants with a thermocline storage tank. Sol. Energy 103, 456-472. doi:10.1016/j.solener.2014.02.037

Biencinto, M., González, L., Valenzuela, L., 2016. A quasi-dynamic simulation model for direct steam generation in parabolic troughs using TRNSYS. Appl. Energy 161, 133-142. 
CIT Energy Management, 2013. Sunstore4 Tool [WWW Document]. URL http://sunstore4.eu/useresults/sunstore4-tool/ (accessed 12.13.16).

Deschaintre, L., 2014. Development of a solar district heating online calculation tool. Energy Procedia 48, 1065-1075. doi:10.1016/j.egypro.2014.02.121

Dorantes, R., García, G., Salazar, C., Oviedo, H., González, H., Alanis, R., Salazar, E., Martín-Dominguez, I.R., 2014. Thermal and hydraulic design of a solar collector field for a primary school pool. Energy Procedia 57, 2515-2524. doi:10.1016/j.egypro.2014.10.262

Drummond, A.J., 1956. On the measurement of sky radiation. Arch. für Meteorol. Geophys. und Bioklimatologie 7, 413-436. doi:10.1007/BF02242969

EMD International A/S, 2016. energyPRO [WWW Document]. URL http://www.emd.dk/energypro/ (accessed 12.13.16).

European Commission, 2016. Communication from the Commission to the European Parliament, the Council, the European Economic and Social Committee and the Committee of the Regions: An EU Strategy on Heating and Cooling. doi:10.1017/CBO9781107415324.004

Furbo, S., Perers, B., Bava, F., 2015. Thermal performance of solar district heating plants in Denmark, in: Conference Proceedings of EuroSun 2014. International Solar Energy Society (ISES), Aix-les-Bains, France. doi:10.18086/eurosun.2014.19.11

Hausner, R., Fechner, H., 1998. Influence of the flow condition (laminar/turbulent) in the fluid tube on the collector efficiency factor of a fin absorber, in: Proceedings of EuroSun 1998 Conference. Portoroz, Slovenia.

ISO, 2014. ISO Standard 9806: Solar energy - Solar thermal collectors - Test methods. Geneva, Switzerland.

Kipp \& Zonen, 2006. CMP/CMA series manual.

Klein, S.A., et al., 2012. TRNSYS 17 A Transient System Simulation program. Solar Energy Laboratory, University of Wisconsin-Madison.

Kong, W., Perers, B., Fan, J., Furbo, S., Bava, F., 2015. A new Laplace transformation method for dynamic testing of solar collectors. Renew. Energy 75, 448-458. doi:10.1016/j.renene.2014.10.026

Lapillonne, B., Pollier, K., Samci, N., 2015. Energy efficiency trends for households in the EU [WWW Document]. URL http://www.odyssee-mure.eu/publications/efficiency-by-sector/household/householdeu.pdf

Le Denn, A., 2014. Solar District Heating Guidelines: Calculation tools and methods [WWW Document]. URL http://solar-district-heating.eu (accessed 12.13.16).

Logstor, 2005. Logstor Industry Catalogue.

Natural Resources Canada, 2016. RETScreen [WWW Document]. URL http://www.nrcan.gc.ca/energy/software-tools/7465 (accessed 12.13.16).

Nielsen, J.E., Battisti, R., 2012. Solar District Heating Guidelines: Feasibility study [WWW Document]. URL http://solar-district-heating.eu (accessed 12.13.16).

Perers, B., Furbo, S., 2014. IEA-SHC Tech Sheet 45.A.4 Simulation of Large Collector Fields [WWW Document]. URL http://task45.iea-shc.org/fact-sheets (accessed 12.13.16).

PlanEnergi, 2013. Fjernsol II [WWW Document]. URL http://www.solarkey.dk/fjernsol.htm (accessed 3.30.17).

Raab, S., Mangold, D., Müller-Steinhagen, H., 2005. Validation of a computer model for solar assisted district heating systems with seasonal hot water heat store. Sol. Energy 79, 531-543. doi:10.1016/j.solener.2004.10.014

Rasmussen, F.L., 2016. Rekordanlæg bliver klar på rekordtid. Fjernvarmen - Dansk Fjernvarmes Mag. 7, 2023.

673 Rasmussen, P.B., Svendsen, S., 1996. SolEff, Program til beregning af solfangeres effektivitet. 
Reiter, P., Poier, H., Holter, C., 2016. Big Solar Graz: Solar district heating in Graz - 500,000 m² for 20\% solar fraction, in: Proceedings of EuroSun 2016 Conference. Palma de Mallorca, Spain.

Saleem, M.S., Haider, A., Abas, N., 2015. Review of Solar Thermal Water Heater simulations using TRNSYS, in: 2nd International Conference on Power Generation Systems and Renewable Energy Technologies, PGSRET 2015. pp. 68-73. doi:10.1109/PGSRET.2015.7312251

Schubert, M., Holter, C., Soell, R., 2010. Solar District Heating (SDH): Technologies used in large scale SDH plants in Graz - Operational experiences and further developments, in: Proceedings of 12th International Symposium on District Heating and Cooling. Tallinn, Estonia, pp. 140-142.

Schwarzbözl, P., 2007. A TRNSYS Model Library for Solar Thermal Electric Components (STEC). Reference Manual.

SDHtake-off, 2012. SDHtake-off - Solar District Heating in Europe.

Sibbitt, B., McClenahan, D., Djebbar, R., Thornton, J., Wong, B., Carriere, J., Kokko, J., 2012. The performance of a high solar fraction seasonal storage district heating system - Five years of operation. Energy Procedia 30, 856-865. doi:10.1016/j.egypro.2012.11.097

SolData, 2016. SolData 80spc Pyranometer - Data and application notes [WWW Document]. URL http://www.soldata.dk/pyr-80spc.htm (accessed 3.30.17).

SP, 2016. Solar Keymark Certificate HTHEATstore 35/08 No. SP SC0843-14. Borås, Sweden.

TESS, 2012. TESSLibs 17 Component Libraries for the TRNSYS Simulation Environment.

Trier, D., 2016. Personal communication with D. Trier (PlanEnergi).

VDI, 2004. VDI-Richtlinie: VDI 6002 Blatt 1 Solare Trinkwassererwärmung - Allgemeine Grundlagen Systemtechnik und Anwendung im Wohnungsbau.

Vela Solaris, 2016. Polysun Simulation Software [WWW Document]. URL http://www.velasolaris.com/ (accessed 3.30.17).

Weiss, W., Spörk-Dür, M., Mauthner, F., 2017. Solar Heat Worldwide - Global Market Development and Trends in 2016 [WWW Document]. URL http://www.solarthermalworld.org/keyword/solar-heatworldwide-2017 (accessed 6.19.17). 